\title{
The impact of longitudinal offending trajectories on mental health: Lifetime
}

consequences and intergenerational transfer

Kim Reising ${ }^{1}$, Maria M. Ttofi ${ }^{2}$, David P. Farrington ${ }^{3}$, \& Alex R. Piquero ${ }^{4}$

${ }^{1}$ Institute of Criminology, University of Cambridge, United Kingdom: kkr29@cam.ac.uk

${ }^{2}$ Institute of Criminology, University of Cambridge, United Kingdom: mt394@cam.ac.uk

${ }^{3}$ Institute of Criminology, University of Cambridge, United Kingdom: dpf1@cam.ac.uk

${ }^{4}$ University of Texas at Dallas, United States of America: apiquero@utdallas.edu

Corresponding Author: Kim Reising, Institute of Criminology, University of Cambridge, Sidgwick Avenue, CB3 9DA, Cambridge, United Kingdom. Email: kkr29@cam.ac.uk 


\title{
The impact of longitudinal offending trajectories on mental health: Lifetime consequences and intergenerational transfer
}

\author{
Abstract \\ Objectives: This paper set out to contribute to the literature by linking research into offending \\ pathways with the study of longitudinal effects and intergenerational transmission of mental \\ health. \\ Methods: Data was used from two generations of the Cambridge Study in Delinquent \\ Development, a longitudinal study of 411 men from London and their children who were \\ followed since 1961-62. \\ Results: Findings from this study (1) indicate that symptoms of depression and anxiety were \\ highest among those who commenced offending in adulthood and (2) demonstrated familial \\ continuity of mental health: poor offspring mental health was related to father's criminality, but \\ not to their offender group. \\ Conclusions: A thorough understanding of the heterogeneity of offenders is essential for policy \\ and practice. It is suggested that future research further examines individuals who only \\ commence offending in adulthood, since they have been shown to not only face a variety of \\ adverse outcomes themselves, but are also likely to have children with distinct patterns of \\ internalizing problems across. \\ Keywords: life-course-persistent offending, late-onset offending, adolescence-limited \\ offending, adverse mental health outcomes, intergenerational transmission
}




\section{Background}

There has been a longstanding debate over the relationship between criminal behavior and mental health (see Monahan et al., 2001). For decades research has discovered increased rates of anxiety and depression among offenders. It is often proposed that antisocial and criminal behavior exert a detrimental effect on the mental health of individuals and families. However, the heterogeneity of offenders has been recognized only relatively recently (e.g., Moffitt, 1993). A better understanding of the patterns of offending underlying the age-crime curve has implications for policy and practice and will help to not only improve treatment of offenders but also offer new opportunities for prevention and intervention regarding the familial transmission of mental health problems. The current study attempts to contribute to the literature by linking research into offending pathways with the study of longitudinal effects and intergenerational transmission of mental health.

\subsection{Offender groups}

One of the most consistent findings in criminology is the existence of the 'age-crime curve' the observation that criminal behavior increases in early adolescence, peaks during the mid-late teenage years, and declines thereafter (e.g., Farrington, 1986). Sociological approaches postulate that this observation is a result of the 'maturity gap' - the incongruity between the age of attainment of biological and social maturity (i.e., adult status) in our society - which interacts with increasing importance of peer context during adolescence (Moffitt, 1993).

In recent years, however, researchers have argued that, although the age-crime curve may be universal, it is not invariant (e.g., Piquero, Farrington, \& Blumstein, 2003). Treating offending individuals as a homogeneous group makes an assumption that there are basic elements which influence how behaviour varies with age - yet, there are essential differences in patterns of offending.

By appreciating different constituents of the aggregate age-crime curve, Moffitt (1993) developed a dual taxonomy which classifies two distinct offender types: the adolescencelimited (AL) offenders, who struggle with the effects of the maturity gap as alluded to above, and the life-course-persistent (LCP) offenders, who offend throughout the life-course and who possess a distinct psychopathology.

More recent research has offered challenges to Moffitt's taxonomy by reporting more offender groups than originally proposed. For the Cambridge Study in Delinquent Development (CSDD), for instance, McGee and Farrington (2010) found a third group of offenders, namely late-onset (LO) offenders, who only commence offending in adulthood (see also Zara \& 
Farrington, 2009). In their systematic review of offender groups, Jolliffe and colleagues (Jolliffe et al. 2017) developed a more consistent definition of different offender groups, including key features such as criminal career onset and duration, which is the basis of this study's conceptualization of offender groups.

\subsection{Offender groups and mental health}

For decades, research has provided evidence that offenders face many adverse outcomes including, for instance, an increased risk of health-related problems and early death (Chassin et al., 2013; Piquero et al., 2007, 2011). At the same time, however, research has primarily examined how risk factors affect different offender groups (e.g., Piquero, 2008), and has paid less attention to the fact that certain patterns of behavior and psychopathology may also be outcomes of distinctive offending pathways. Moffitt (2006) hypothesized that different offending pathways may bear differential risks for adult mental health. Our literature review indicates that there are only very few studies that have made specific predictions about healthrelated outcomes based on Moffitt's offender typology.

Using data from the Dunedin Multidisciplinary Health and Development Study, Moffitt and colleagues (2002), as well as Odgers and colleagues (2007), found that AL and LCP offenders had significantly higher levels of mental health problems than unclassified men, with LCP offenders experiencing more extreme symptoms. Equivalent results have been found by Piquero and colleagues (2007) for mental health outcomes of LCP and AL offenders in the National Collaborative Perinatal Project.

Capaldi (1992) suggested that early-onset offending could interfere with the development of important competencies, which may limit future opportunities in education and work, and thereby make chronically antisocial individuals more vulnerable to mental health problems (see Laub \& Sampson, 2001; Wiesner, Capaldi \& Patterson, 2003). Limited involvement in conventional activities and relationships could mean constant stress and adverse societal reactions (stigma and official labelling processes), which seem important mechanisms for the development of internalizing problems (Becker, 1963; Siennick, 2007). Moffitt (1993) conceptualized LCP offenders as having increased neuropsychological vulnerability ("lifecourse-persistent antisocial behavior is a form of psychopathology", p.679), which could indicate that LCP offenders have personality traits that are associated with generally higher psychological vulnerability. 


\subsection{Intergenerational transmission}

Offenders not only face lifelong disadvantages themselves, but they may have children who go on to experience similar difficulties. Research suggests that parental offending is associated with a range of offspring adverse outcomes (e.g., Farrington, Ttofi, \& Crago, 2017; Loeber et al., 2009; Capaldi, Pears, \& Owen, 2008). The process by which parents influence their children is described as intergenerational transmission. The family is a prime location for socialization in the development of children's values, attitudes, and behavior patterns. Parental offending could interfere with family functioning and, together with adverse living circumstances and socialization practices, contribute to offspring internalizing problems.

Importantly, however, the intergenerational transmission of adverse outcomes might be different for parents with different offending pathways. To date, there are only very few studies examining offspring outcomes over the life-course based on parental offender groups.

Using data from the CSDD and the Dutch Transfive Study, Besemer and Farrington (2012) demonstrated that the offspring of offenders showed significantly more offending behavior than the offspring of non-offenders. For the Stockholm Birth Cohort Study sample, a similar trend was obtained, but children's convictions were related to the fact that fathers had a conviction, but not to their offender group (Besemer, Axelsson, \& Sarnecki, 2016).

Laub and Sampson (1988) hypothesized that parental offending operates through adverse parenting practices (e.g., neglectful or harsh parenting), which in turn increase children's risk of delinquency (Smith \& Farrington, 2004). Social learning theory suggests that children of parents with behavioral problems will replicate them in their own behavior if they are encouraged or not effectively disciplined (Burgess \& Akers, 1966). According to Merton's strain theory (1938) the children of offenders in disadvantaged environments (e.g., low SES, structurally disadvantaged neighborhoods) may perceive crime as the only or most efficient way to achieve certain goals (i.e., there is an imbalance of desirable goals and available means). Research has also shown that children of parents with mental illnesses are at greater risk of developing internalizing problems. Several studies examining multi-generational mental health relationships have found significant associations between internalizing problems across generations (Hancock et al., 2013; Johnston, Schurer, \& Shields, 2011). One potential pathway for the transmission of mental health within the family unit is through genetic mechanisms (Rutter, 2006). Additionally, it has been suggested that internalizing problems of children may contribute to ineffective parenting practices (e.g., Conger et al., 1994), which in turn may increase children's risk of emotional and mental health problems (Laub \& Sampson, 1988). Unstable living circumstances may force children to face major life events, like taking over 
family responsibilities, demands they may not yet be sufficiently prepared for (Wickrama, Conger, Wallace, \& Elder, 2003).

To date, research has been able to demonstrate the familial continuity of offending behavior as well as mental health problems. However, to the best of our knowledge, very few studies have distinguished various developmental pathways of criminal behavior and no study has examined offspring mental health in relation to on different parental offender groups.

\subsection{Gender Aspects}

Previous research suggests that the familial continuity of certain forms of psychopathology may be more distinct in girls than in boys. Research has shown consistent gender differences in the prevalence of internalizing and externalizing problems in the general population, with females at heightened risk for internalizing and males for externalizing symptoms (for a review see Zahn-Waxler, Shiftcliff \& Marceau, 2008). By drawing on conceptions of gender roles in Western societies, approaches to women's health offer explanations for these differences. Based on mechanisms by which socialization processes influence the experience and expression of mental health problems of women, it is suggested that females might not only be more likely to overinternalize their own and others' problems, but may also be more likely to define their own experiences in psychiatric terms (e.g., Keenan \& Shaw, 1997).

The main objective of this paper is to investigate the longitudinal and intergenerational impact of criminal behavior on mental health problems by testing the following hypotheses:

\section{Offenders' mental health}

- Early onset offenders (AL and LCP) have more mental health problems than those who commence offending in adulthood (LO).

- Persistent offenders (LCP) show more extreme symptoms regarding internalizing problems.

\section{Intergenerational transmission of mental health}

- Fathers and offspring have similar mental health status.

- Paternal mental health has a stronger impact on daughters' internalizing problems than on sons. 
Offspring mental health by fathers offending pathway

- Offspring of adult offending fathers (LCP and LO) have increased mental health problems compared to offspring of AL offending fathers.

- Paternal crime has a stronger impact on daughters' internalizing problems than on sons' internalizing problems.

\section{Methods}

\subsection{Sample}

Hypotheses are tested using data from the Cambridge Study in Delinquent Development (CSDD), a prospective longitudinal study of the development of offending behavior among 411 males from South London who were born around 1953. At age 8,94\% of the boys could be classified as working-class, based on their fathers' occupations, and most described themselves as White and of British origin (87\%). The majority of boys were living in traditional two-parent families (Farrington 2003).

Since 1961-62, the males have been studied at frequent intervals using a multi-informant approach (self-, parent-, teacher-, and peer-reports). Information has been obtained on individual, family, school, and social characteristics. Additionally, conviction and medical records have been studied (Farrington et al., 2013). Between 2004 and 2007, the biological children of the original men were followed up, leading to interviews with 551 children $(84.4 \%$ of those eligible - Farrington, Ttofi, Crago, \& Coid 2015).

\subsection{Measures}

\section{Criminal convictions}

Convictions were counted if they were for 'standard list' offenses committed between ages 10 and 56, including minor offenses such as shoplifitng, as well as more serious offenses ranging from robbery to sexual offenses.

The CSDD sample includes 253 fathers, of whom 112 (44.3\%) committed an offense between the ages of 10 and 56. In previous analyses, distinct offender groups for study males were estimated based on Moffitt's (1993) taxonomy. The results of these analyses favored a fourgroup solution including: non-convicted $(\mathrm{NC}-55.7 \%)$, late-onset ( $\mathrm{LO}-9.8 \%)$, adolescencelimited ( $\mathrm{AL}-20.7 \%)$, and life-course persistent (LCP - 13.8\%) offenders (Jolliffe et al., 2017). LCP offenders were defined as those who committed their first offense before age 20 and then at least another offense at age 30 or later. Similarly, AL offenders were labelled as such if they committed their first offense before age 20 and their last offense before age 30 . LO offenders 
were classified as those who only commenced offending at age 20 or later. Figure 1 shows the different age-crime curves for fathers' ${ }^{1}$ offending groups over the life-course.

\section{INSERT FIGURE 1 ABOUT HERE}

\section{Depression and Anxiety}

Symptoms of internalizing problems were measured using the General Health Questionnaire (GHQ-30), which was designed to capture non-psychotic psychiatric disorders using 30 items in community samples (Goldberg 1972). For the present study only the two depression and anxiety subscales were used, which were identified in previous analyses and highly congruent with those found in previous studies (e.g., Huppert, Walter, \& Day 1989). A factor analysis yielded a four-item scale for depression (Likert scoring: 0 to 12; age $32 \alpha=0.86$, age $48 \alpha=$ 0.87 ) and a ten-item scale for anxiety (Likert scoring: 0 to 30; age $32 \alpha=0.92$, age $48 \alpha=0.94$ ).

\subsection{Analytic Approach}

A three-stage analytical approach was used to investigate the longitudinal and intergenerational link between offending pathways and internalizing problems.

First, dichotomized mental health problems for each offender group were examined, using conditional odds ratios (OR) obtained from a series of separate logistic regression analyses. In a second step, offspring's and fathers' mental health status was compared, using logistic regression analyses. In the last step, offspring mental health was investigated across fathers' offender group classification using negative binomial regression analyses for skewed distributions (Byers, Allore, Gill, \& Peduzzi, 2003). For the last two analyses, a generalized estimating equations (GEE) approach was applied to estimate overall relationships between variables over time, because analyses of family data require statistical techniques that take into account the shared variance of outcomes within families (i.e., children clustered within fathers) (Liang \& Zeger, 1986). GEE models are specified using an exchangeable correlation matrix, since it is more appropriate for clustering at the family level (Ballinger, 2004).

\footnotetext{
${ }^{1}$ In this study, 'fathers' describes a subsample of the original study males, namely those who have a child of their own.
} 


\section{Results}

\subsection{Mental health problems per offender group}

The first question concerned the extent to which fathers' offending pathways coincide with their mental health problems at ages 32 and 48. For further analyses, males were categorized into positive and negative cases for depression and anxiety, based on an approach that identified the $15 \%$ with the highest score as positive cases. For this study the main interest was to examine individuals with clear symptoms. It was assumed that the positive group, made up of those $15 \%$ with the highest scores, was more likely to actually suffer from symptoms of depression or anxiety.

\section{INSERT TABLE 1 ABOUT HERE}

The results, presented in Table 1, reveal that early and mid-adulthood symptoms of internalizing problems were the highest among LO offenders (39.1\% and 47.6\%). LO offenders were significantly more likely than non-convicted fathers to show internalising problems $\left(\mathrm{OR}_{32}=\right.$ $3.10, \mathrm{p}<.01$ and $\left.\mathrm{OR}_{48}=2.96, \mathrm{p}<.05\right)$. Similarly, age 32 internalizing problems were relatively more likely among LCP offenders compared to non-convicted males $\left(\mathrm{OR}_{32}=2.41, \mathrm{p}<.05\right)$. However, at age 48 LCP offenders did not show significantly higher levels of anxiety or depression $\left(\mathrm{OR}_{48}=.91, \mathrm{p}=.456\right)$. AL offenders' mental health problems were not statistically significantly elevated $\left(\mathrm{OR}_{32}=1.70, \mathrm{p}=.091\right.$ and $\left.\mathrm{OR}_{48}=.92, \mathrm{p}=.477\right)$.

A closer look at the type of condition reveals that for LO offenders the most common mental health problem at age 32 was anxiety (30.4\%), while at age 48 it was depression (38.1\%). Compared to non-convicted males, being a LO offender is significantly associated with whether a father develops anxiety during early adulthood, $\mathrm{OR}_{32}=3.47(\mathrm{p}<0.01)$ and depression during mid-adulthood, $\mathrm{OR}_{48}=4.16(\mathrm{p}<.01)$. Similarly, early adulthood depression (age 32: $\left.26.1 \%\right)$ and symptoms of anxiety (33.3\%) later in life at age 48 were also highest among LO offenders. A more detailed exploration of conditions for LCP offenders shows a similar pattern, with anxiety being more prevalent at age $32(24.2 \%)$ and depression being more prevalent at age 48 $(15.6 \%)$. LCP offenders had 2.54 times the odds $(\mathrm{p}<.05)$ of non-convicted males to develop anxiety during early adulthood.

\subsection{Offspring mental health versus father mental health}

The next question is whether fathers' mental health status predicts offspring mental health. CSDD study males had 551 children $\left(M_{\text {age }}=25.5\right)$, of whom $291(52.8 \%)$ were male and 260 
$(47.2 \%)$ were female. For reasons of comparability, the same classification approach was used to categorize offspring into positive and negative cases regarding their symptoms of depression and anxiety. The results of the relationship between paternal and offspring mental health symptoms are presented in Table 2.

\section{INSERT TABLE 2 ABOUT HERE}

Overall, the GEE models reveal that the children of anxious or depressed fathers have an increased risk of developing internalizing problems. However, the results show only marginal trends towards significance. Even though more than one-fifth $(21.4 \%)$ of children with depressed fathers at age 32 showed higher levels of depression, they were not significantly more likely than children with non-case fathers $(14.1 \%)$ to develop depression, $\mathrm{OR}_{32}=1.66, \mathrm{p}=.066$. Similarly, children of age 48 depressed fathers $(21.6 \%)$ do not have a statistically significant increased risk to develop depression $\left(\mathrm{OR}_{48}=1.69, \mathrm{p}=.070\right)$.

The same pattern can be found for anxiety. Children of anxious fathers $(20.8 \%$ and $21.6 \%)$ are not statistically significantly more likely than their counterparts with non-case fathers $(14.3 \%$ and $13.8 \%)$ to develop anxiety $\left(\mathrm{OR}_{32}=1.57, \mathrm{p}=.072 ; \mathrm{OR}_{48}=1.72, \mathrm{p}=.054\right)$.

However, when GEE models are estimated for sons and daughters separately, analyses reveal interesting differences. Paternal depression seems to primarily effect sons' mental health, while paternal anxiety effects daughters' mental health. Sons of fathers with early and mid-adulthood depression had more than twice the odds of sons with non-case fathers to develop depression themselves $\left(\mathrm{OR}_{32}=2.03, \mathrm{p}<.05\right.$ and $\left.\mathrm{OR}_{48}=2.33, \mathrm{p}<.05\right)$. A similar pattern is found for daughters' anxiety. Daughters with fathers who are classified as anxious at age 32 had almost twice the odds to also develop anxiety $\left(\mathrm{OR}_{32}=1.95, \mathrm{p}=.057\right)$, while those with age 48 anxious fathers had 2.38 times the odds of daughters with non-case fathers to develop anxiety $\left(\mathrm{OR}_{48}=\right.$ $2.38, \mathrm{p}<.05)$.

\subsection{Offspring mental health versus father offender group}

The last step examines whether fathers' offending pathways predict offspring mental health. Overall, the results in Table 3 show that, compared to non-offending fathers, offending fathers had higher proportions of children with anxiety or depression. Nearly one-fifth (18.0\%) of the children of LO offenders were children with depression during early adulthood. The proportion of depressed children among AL offenders was similarly high, with $16.1 \%$ of all children 
showing symptoms. Interestingly, LCP offenders had a relatively small proportion of children with symptoms of depression (12.1\%), even smaller than non-convicted fathers $(14.5 \%)$. Looking separately at sons and daughters, the results showed that LO and LCP offenders had a higher proportion of depressed daughters (25.0\% and 16.2\%), while AL offenders had a higher proportion of depressed sons $(21.7 \%)$. Among non-convicted fathers, there was no difference in the proportions of depressed sons and daughters.

The highest proportion of children with anxiety symptoms is found among LCP offenders (18.2\%). This is followed by AL offenders of whom $16.9 \%$ had children with anxiety. The proportion of anxious children among LO offenders was slightly smaller (14.0\%) and does not significantly differ from the proportion of anxious children among non-convicted fathers (13.9\%). Non-convicted fathers had equal proportions of anxious sons and daughters (13.7\% and $14.1 \%$ ). For all other offender groups, the proportion of anxious daughters was significantly higher than the proportion of anxious sons.

\section{INSERT TABLE 3 ABOUT HERE}

Overall, the GEE models reveal that for the whole sample of children, fathers' offending behavior did not significantly predict children's internalizing symptoms. However, when examining sons and daughters separately, fathers classified as LO offenders were statistically significantly less likely than non-convicted fathers to have anxious sons (OR = .71, p <.05). Additionally, sons of LO offenders were statistically less likely to develop depression (OR = $.42, \mathrm{p}<.05)$.

Only one analysis reveals significance for a positive association between fathers' offending pathways and children's internalizing symptoms. Daughters of AL offenders had 1.22 times the odds $(\mathrm{p}<.05)$ of daughters with non-convicted fathers to show symptoms of anxiety.

\section{Discussion}

This paper set out to contribute to the literature by linking research into offending pathways with the study of longitudinal effects and intergenerational transmission of mental health, using data from two generations of the CSDD.

\subsection{Offender's mental health}

Our analysis of offenders' mental health reveals two interesting findings. First, in contrast to previous research, symptoms of depression and anxiety were not highest among early-onset 
offenders (LCP and AL), but among those who only commenced offending in adulthood (LO). This is particularly interesting, since our analysis of childhood features has suggested that this group approaches the transition into adulthood with less severe challenges and more resources. However, Arnett's (2000) concept of 'emerging adulthood' offers a possible explanation by proposing another 'maturity-gap' for young adults (ages 18-29), similar to those of adolescents, in which life transitions and experiences (i.e., identity exploration, instability, a sense of broad possibilities) may relate to adult-onset offending through mechanisms similar to those of the traditional maturity gap.

Our second finding points to a developmental sequence of mental health problems among persistent offenders (i.e., early-adulthood anxiety, mid-adulthood depression). It might be that chronically antisocial individuals have always experienced internalizing problems, which for LO offenders, for instance, may have played a role in delaying criminal behavior until adulthood (Zara \& Farrington, 2009). However, even when this 'protective' effect of anxiety wears off with age, the symptoms may remain present during early adulthood. Early internalizing problems could also be related to later symptoms of depression. Individuals may find themselves unprepared to cope with the difficulties of adulthood, and those with chronic antisocial behavior may be more vulnerable to depression (Defoe, Farrington, \& Loeber, 2013; Capaldi, 1992).

\subsection{Intergenerational transmission of mental health}

The findings of our second analysis are broadly consistent with other studies that have demonstrated the familial continuity of mental health. The children of diseased fathers were at greater risk for developing internalizing problems themselves. The potential pathways may include genetic mechanisms, parenting practices, and family circumstances that limit future prospects (Rutter, 2006; Laub \& Sampson, 1988).

\subsection{Offspring mental health of offending fathers}

In line with current research, the findings of our third analysis demonstrate an overall effect of paternal offending on children's mental health, with a higher percentage of symptomatic daughters than sons. Generally, offspring mental health seems to be related to fathers' criminality but not particularly to their offender group. The results reveal gender differences in internalizing problems, with the daughters of offending fathers being slightly more at risk for mental health problems than the sons. Approaches to women's health suggest that early problems in the children of offenders may be channelled into predominantly internalizing 
problems for girls relative to boys, since parents may be generally more accepting of fearful and withdrawn behavior in girls. Zahn-Waxler and colleagues (1991) have hypothesized that, due to early life socialization of empathy in girls, exposure to chronic distress of others may lead to an overinternalization of their own and others' problems and thereby shape girls' problem behavior into an internalized form.

Interestingly, although the findings indicate that persistent offenders are at risk for poor mental health, for which a strong intergenerational transmission has been found, their sons are significantly less likely to develop internalizing problems. In line with assumptions about gendered socialization practices, it might be that early problems in boys are channelled into externalizing forms.

\subsection{Limitations and future directions}

It is important to note a few limitations of this study: First, the numbers of offending parents were relatively small. Due to extremely small numbers of convicted mothers, intergenerational transmission was solely assessed based on paternal measures. Second, the offending pathways were estimated using official records, which only capture a fraction of the true number of offenses committed and may thereby have affected the composition of offender groups. Third, the GHQ-30 is not a clinically standardized instrument to detect mental health problems; therefore, individuals may not always have been successfully identified.

Despite these limitations, this study contributes to the literature by being the first to date to investigate the intergenerational transmission of mental health based on fathers' offending pathways. A more thorough understanding of the heterogeneity of offenders is essential for policy and practice. This is particularly important concerning the extent to which some individuals with distinct offending pathways experience adverse health outcomes. It is suggested that future research should further examine adult offenders, particularly LO offenders, who are often neglected in criminological research; they have been shown to not only face a variety of adverse outcomes themselves, but are also very likely to have children with distinct patterns of internalizing problems across the life course. 


\section{References}

Arnett, J.J. (2000). Emerging adulthood: A theory of development from the late teens through the twenties. American Psychologist, 55, 469-480.

Ballinger, G.A. (2004). Using generalized estimating equations for longitudinal data analysis. Organizational Research Methods, 7, 127-150.

Becker, G.M. (1963). Outsiders: Studies in the sociology of deviance. New York: Free Press.

Besemer, S., \& Farrington, D.P. (2012). Intergenerational transmission of criminal behavior: Conviction trajectories of fathers and their children. European Journal of Criminology, $9(2), 120-141$.

Besemer, S, Axelsson, J., \& Sarnecki, J. (2016). Intergenerational transmission of trajectories of offending over three generations. Journal of Developmental and Life-Course Criminology, 2, 417-441.

Burgess, R.L., \& Akers, R.L. (1966). A differential association-reinforcement theory of criminal behavior. Social Problems, 14(2), 128-147.

Byers, A.L., Allore, H., Gill, T.M., \& Peduzzi, P.N. (2003). Application of negative binomial modelling for discrete outcomes: A case study in aging research. Journal of Clinical Epidemiology, 56(6), 559-564.

Capaldi, E.J. (1992). The organization of behavior. Journal of Applied Behavior Analysis, 25(3), 575-577.

Capaldi D.M., Pears K.C., \& Owen, L.D. (2008). A prospective three generational study of fathers' constructive parenting. Developmental Psychology, 45(5), 1257-1275.

Chassin, L., Piquero, A.R., Losoya, S.H., Mansion, A.D., \& Schubert, C.A. (2013). Joint consideration of the distal and proximal predictors of premature mortality among serious juvenile offenders. Journal of Adolescent Health, 52, 689-696.

Conger, R.D., Ge, X. Elder, G.H., Lorenz, F.O., \& Simons, R.L. (1994). Economic stress, coercive family process, and developmental problems of adolescents. Child Development, $65,541-561$.

Defoe, I.N., Farrington, D.P., \& Loeber, R. (2013). Disentangling the relationship between delinquency and hyperactivity, low achievement, depression, and low socioeconomic status: Analysis of repeated longitudinal data. Journal of Criminal Justice, 41, 100-107. 
Farrington, D.P. (1986). Age and Crime. In M. Tonry and N. Morris (Eds.), Crime and Justice: An annual review of research, (vol. 7, pp.189-250). Chicago: University of Chicago Press.

Farrington, D.P. (2003). Key results from the first 40 years of the Cambridge Study in Delinquent Development. In T.P. Thornberry and M.D. Krohn (Eds.), Taking stock of delinquency: An overview of findings from contemporary longitudinal studies, (pp.137183). New York: Kluwer/Plenum.

Farrington, D.P., Piquero, A.R., \& Jennings, W.G. (2013). Offending from childhood to late middle age: Recent results from the Cambridge Study in Delinquent Development. New York: Springer.

Farrington, D.P., Ttofi, M.M., \& Coid, J.W. (2009). Development of adolescence-limited, lateonset, and persistent offenders from age 8 to age 48. Aggressive Behavior, 35(2), 150-163.

Farrington, D.P., Ttofi, M.M., \& Crago, R.V. (2017). Intergenerational transmission of convictions for different types of offences. Victims and Offenders, 12, 1-20.

Farrington, D.P., Ttofi, M.M., Crago, R.V., \& Coid, J.W. (2015). Intergenerational similarities in risk factors for offending. Journal of Developmental and Life-Course Criminology, 1, 48-62.

Goldberg, D. (1972). The detection of psychiatric illness by questionnaire: A technique for the identification and assessment of non-psychotic psychiatric illness. London, New York: Oxford University Press.

Hancock, K.J., Mitrou, F., Shipley, M., Lawrence, D., \& Zubrick, S.R. (2013). A three generation study of the mental health relationships between grandparents, parents and children. BMC Psychiatry, 13(299).

Huppert, F.A., Walters, D.E., \& Day, N.E. (1989). The factor structure of the General Health Questionnaire (GHQ-30): a reliability study on 6317 community residents. British Journal of Psychiatry, 155, 178-185.

Johnston, D.W., Schurer, S., \& Shields M.A. (2011) Evidence on the long shadow of poor mental health across three generations. IZA Discussion Paper No. 6014.

Jolliffe, D., Farrington, D.P., Piquero, A.R., MacLeod, J.F., \& van de Weijer, S. (2017). Prevalence of life-course-persistent, adolescence-limited, and late-onset offenders: A 
systematic review of prospective longitudinal studies. Aggression and Violent Behavior, $33,4-14$.

Kaufman, J.M. (2009). Gendered responses to serious strain: The argument for a general strain theory of deviance. Justice Quarterly, 26(3), 410-444.

Keenan, K., \& Shaw, D. (1997). Developmental and social influences on young girls' early problem behavior. Psychological Bulletin, 121, 95-113.

Laub, J.H., \& Sampson, R.J. (1988). Unravelling families and delinquency: A reanalysis of the Gluecks' data. Criminology, 26(3), 355-380.

Laub, J.H., \& Sampson, R.J. (2001). Understanding desistance from crime. Crime and Justice, 28, 1-69.

Liang, K.Y., \& Zeger, S.L. (1986). Longitudinal data analysis using generalized linear models. Biometrika, 73(1), 13-22.

Loeber, R., Pardini, D.A., Hipwell, A., Stouthamer-Loeber, M., Keenan, K., \& Sembower, M.A. (2009): Are there stable factors in preadolescent girls' externalizing behaviors? Journal of Abnormal Child Psychology, 37, 777-791.

McGee, T.R., \& Farrington, D.P. (2010). Are there any true adult-onset offenders? The British Journal of Criminology 50(3), 530-549.

Merton, R.K. (1938). Social structure and anomie. American Sociological Review, 3(5), 672682.

Mirowsky, J., \& Ross, C.E. (1992). Age and depression. Journal of Health and Social Behavior, 33, 187-205.

Moffitt, T.E. (1993). Adolescence-limited and life-course-persistent behavior: A developmental taxonomy. Psychological Review, 100, 674-701.

Moffitt, T.E. (2006). Life-course-persistent versus adolescence-limited antisocial behavior: In D. Cicchetti, \& D.J. Cohen (Eds.), Developmental psychopathology: Vol 3. Risk, disorder, and adaption ( $2^{\text {nd }}$ ed., pp.570-598). Hoboken, NJ: John Wiley \& Sons.

Moffitt, T.E., Caspi, A., Harrington, H., \& Milne, B.J. (2002). Males on the life-coursepersistent and adolescence-limited antisocial pathways: Follow-up at age 26 years. Development and Psychopathology, 14(1), 179-207. 
Monahan, J., Steadman, H., Silver, E., Appelbaum, P., Robbins, P., Mulvey, E., Roth, L., Grisso, T., \& Banks, S. (2001). Rethinking risk assessment: The MacArthur study of mental disorder and violence. New York: Oxford University Press.

Odgers, C.L., Caspi, A., Broadbent, J.M., Dickson, N., Hancox, R.J., Harrington, H., Poulton, R., Sears, M.R., Thomson, W.M., \& Moffitt, T.E. (2007). Prediction of differential health burden by conduct problem subtypes in males. Archives of General Psychology, 64(4), 476-484.

Piquero, A.R. (2008). Taking stock of developmental trajectories of criminal acitivity over the life course. In A. Liberman (Ed.), The long view of crime: A synthesis of longitudinal research, (pp.23-78). New York: Springer.

Piquero, A.R., Daigle, L.E., Gibson, C., Piquero, N.L., \& Tibbetts, S.G. (2007). Are life-coursepersistent offender at risk for adverse health outcomes? Journal of Research in Crime and Delinquency, 44, 185-207.

Piquero, A.R., Farrington, D.P., \& Blumstein, A. (2003). The criminal career paradigm. In M. Tonry (Ed.). Crime and Justice: A review of research (Vol. 30, pp.359-506). Chicago: University of Chicago Press.

Piquero, A.R., Leah, E.D., Gibson, C., Piquero, N.L., \& Tibbetts, S.G. (2007). Are life-coursepersistent offenders at risk for adverse health outcomes? Journal of Research in Crime and Delinquency, 44, 185-207.

Piquero, A.R., Shepherd, I., Shepherd, J., \& Farrington, D.P. (2011). Impact of offender trajectories on health: Disability, hospitalization, and death by middle age in the Cambridge Study in Delinquent Development. Criminal Behavior and Mental Health, 21, 189-201.

Rutter, M. (2006). Implications of resilience concepts for scientific understanding. Annals of the New York Academy of Science, 1094, 1-12.

Siennick, S.E. (2007). The timing and mechanisms of the offending-depression link. Criminology, 45(3), 583-615.

Smith, C.A., \& Farrington, D.P. (2004). Continuities in antisocial behavior and parenting across three generations. Journal of Child Psychology and Psychiatry, 45, 230-247. 
Wickrama, K.A.S., Conger, R.D., Wallace, L.E., \& Elder, G.H. (2003). Linking early risks to impaired physical health of young adults. A perspective on the transition to adulthood. Journal of Health and Social Behavior, 44, 61-74.

Wiesner, M., Capaldi, D.M., \& Patterson, G.R. (2003). Development of antisocial behavior and crime across the life-span from a social interactional perspective: The coercion model. In R.L. Akers and G.F. Jensen (Eds.), Social learning theory and the explanation of crime: A guide for the new century: Advances in criminological theory, (Vol. 11, pp. 317-337). Piscataway, NJ: Transaction.

Zahn-Waxler, C., Cole, P.M., \& Barrett, K.C. (1991). Guilt and empathy: Sex differences and implications for the development of depression. In J. Garber and K.A. Dodge (Eds.), The development of emotion regulation and dysregulation. Cambridge Studies in Social and Emotional Development. Cambridge: Cambridge University Press.

Zahn-Waxler, C., Shiftcliff, E.A., \& Marceau, K. (2008). Disorders of childhood and adolescence: Gender and psychopathology. Annual Review of Clinical Psychology, 4, 275303.

Zara, G., \& Farrington, D.P. (2009). Childhood and adolescent predictors of late onset criminal careers. Journal of Youth and Adolescence, 38, 287-300. 
Figures and Tables

Figure 1: Age crime curves for fathers' offending groups

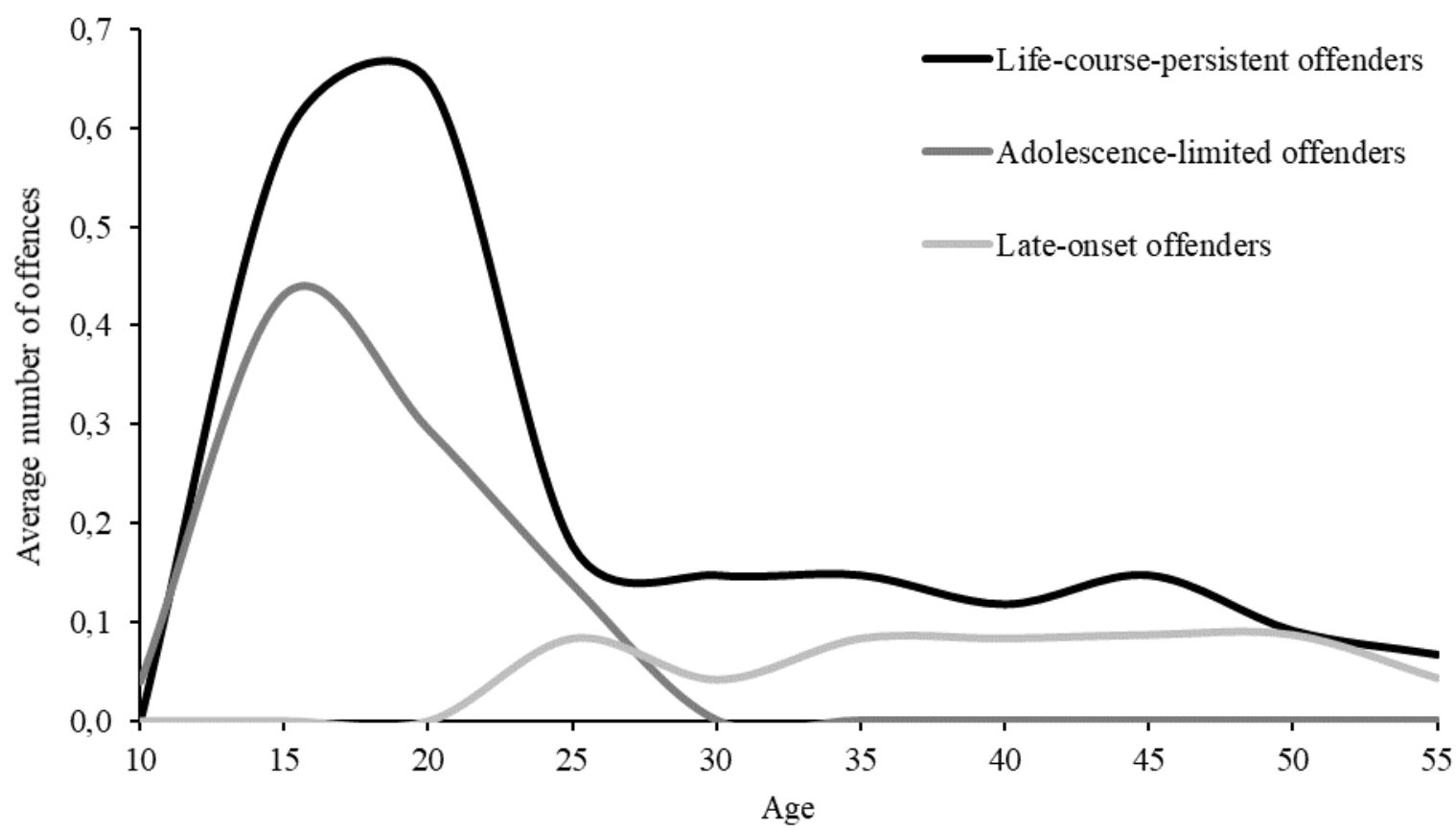

Note: Smoothed line-graph based on authors' own calculations. 
Table 1: Mental health outcomes for different offender groups

\begin{tabular}{|c|c|c|c|c|c|c|c|c|c|c|c|c|c|c|c|c|c|}
\hline & \multicolumn{2}{|c|}{ NC } & \multicolumn{2}{|c|}{ LO } & \multicolumn{2}{|c|}{$\mathbf{A L}$} & \multicolumn{2}{|c|}{ LCP } & \multicolumn{3}{|c|}{ LO versus NC } & \multicolumn{3}{|c|}{ AL versus $N C$} & \multicolumn{3}{|c|}{ LCP versus NC } \\
\hline & $\mathrm{n}$ & $\%$ & $\mathrm{n}$ & $\%$ & $\mathrm{n}$ & $\%$ & $\mathrm{n}$ & $\%$ & OR & p-value & $90 \% \mathrm{CI}$ & OR & p-value & $90 \% \mathrm{CI}$ & OR & p-value & $90 \%$ CI \\
\hline $\mathrm{D} \mid \mathrm{A} 32$ & 23 & 17.2 & 9 & 39.1 & 13 & 26.0 & 11 & 33.3 & 3.102 & 0.010 & $1.398-6.884$ & 1.696 & 0.091 & $0.885-3.251$ & 2.413 & 0.022 & $1.181-4.930$ \\
\hline $\mathrm{D} \mid \mathrm{A} 48$ & 31 & 23.5 & 10 & 47.6 & 11 & 22.0 & 7 & 21.9 & 2.962 & 0.013 & $1.339-6.553$ & .919 & 0.416 & $0.477-1.770$ & .912 & 0.456 & $0.418-1.990$ \\
\hline D32 & 16 & 11.9 & 6 & 26.1 & 9 & 18.0 & 7 & 21.2 & 2.603 & 0.040 & $1.063-6.377$ & 1.619 & 0.145 & $0.766-3.421$ & 1.986 & 0.086 & $0.869-4.538$ \\
\hline A32 & 15 & 11.2 & 7 & 30.4 & 8 & 16.0 & 8 & 24.2 & 3.471 & 0.010 & $1.453-8.296$ & 1.511 & 0.756 & $0.694-3.290$ & 2.539 & 0.029 & $1.134-5.684$ \\
\hline D48 & 17 & 12.9 & 8 & 38.1 & 7 & 14.0 & 5 & 15.6 & 4.163 & 0.003 & $1.772-9.778$ & 1.101 & 0.421 & $0.497-2.438$ & 1.253 & 0.342 & $0.506-3.105$ \\
\hline $\mathrm{A} 48$ & 21 & 15.9 & 7 & 33.3 & 5 & 10.0 & 4 & 12.5 & 2.643 & 0.031 & $1.123-6.222$ & .587 & 0.157 & $0.246-1.397$ & .755 & 0.316 & $0.288-1.976$ \\
\hline
\end{tabular}

Note: $\quad \mathrm{NC}=$ non-convicted, $\mathrm{LO}=$ late-onset offenders, $\mathrm{AL}=$ adolescence-limited offenders, $\mathrm{LCP}=$ life-course-persistent offenders.

$\mathrm{D} \mid \mathrm{A} 32=$ either depressed or anxious at age 32, D|A48 = either depressed or anxious at age 48.

Cut off for depression and anxiety is top $15 \%$.

Percentage (\%) refers to number of males with mental health problems within offender subgroup.

Reference category for odds ratios is non-convicted study males.

One-tailed p-values and confidence intervals because of directional predictions; $90 \% \mathrm{CI}=$ confidence interval. 
Table 2: Impact of fathers' mental health status on offspring internalizing symptoms

\begin{tabular}{|c|c|c|c|c|c|c|c|c|c|c|c|c|c|c|}
\hline & \multicolumn{8}{|c|}{ Fathers' status } & \multicolumn{6}{|c|}{ Odds Ratio } \\
\hline & \multicolumn{4}{|c|}{ Age 32} & \multicolumn{4}{|c|}{ Age 48} & \multirow{2}{*}{\multicolumn{3}{|c|}{$\begin{array}{c}\text { Age } 32 \\
\text { case vs no-case }\end{array}$}} & \multirow{2}{*}{\multicolumn{3}{|c|}{$\begin{array}{c}\text { Age } 48 \\
\text { case vs no-case }\end{array}$}} \\
\hline & \multicolumn{2}{|c|}{ case } & \multicolumn{2}{|c|}{ no-case } & \multicolumn{2}{|c|}{ case } & \multicolumn{2}{|c|}{ no-case } & & & & & & \\
\hline & $\mathrm{n}$ & $\%$ & $\mathrm{n}$ & $\%$ & $\mathrm{n}$ & $\%$ & $\mathrm{n}$ & $\%$ & OR & p-value & $90 \% \mathrm{CI}$ & OR & p-value & $90 \% \mathrm{CI}$ \\
\hline \multicolumn{15}{|c|}{$\%$ depressed or anxious } \\
\hline Total & 112 & 26.8 & 425 & 20.7 & 121 & 23.1 & 401 & 21.2 & 1.384 & .092 & $.927-2.067$ & 1.117 & .341 & $.715-1.744$ \\
\hline Sons & 55 & 29.1 & 230 & 19.1 & 62 & 21.0 & 209 & 20.6 & 1.706 & .056 & $.982-2.965$ & 1.022 & .478 & $.545-1.917$ \\
\hline Daughters & 57 & 24.6 & 195 & 22.6 & 59 & 25.4 & 192 & 21.9 & 1.129 & .367 & $.628-2.031$ & 1.195 & .307 & $.669-2.134$ \\
\hline \multicolumn{15}{|c|}{$\%$ depressed } \\
\hline Total & 70 & 21.4 & 467 & 14.1 & 74 & 21.6 & 448 & 14.1 & 1.658 & 066 & $.956-2.876$ & 1.686 & .070 & $.941-3.020$ \\
\hline Sons & 37 & 24.3 & 248 & 13.7 & 37 & 27.0 & 234 & 13.7 & 2.027 & .047 & $1.012-4.060$ & 2.334 & .031 & $1.105-4,928$ \\
\hline Daughters & 33 & 18.2 & 219 & 14.6 & 37 & 16.2 & 214 & 14.5 & 1.267 & .329 & $.526-3.049$ & 1.148 & .400 & $.469-2.811$ \\
\hline \multicolumn{15}{|c|}{$\%$ anxious } \\
\hline Total & 77 & 20.8 & 460 & 14.3 & 74 & 21.6 & 448 & 13.8 & 1.565 & .072 & $.947-2.587$ & 1.723 & .054 & $.989-3.002$ \\
\hline Sons & 36 & 13.9 & 249 & 12.4 & 39 & 12.8 & 232 & 12.1 & 1.170 & .371 & $.533-2.566$ & 1.150 & .381 & $.540-2.450$ \\
\hline Daughters & 41 & 26.8 & 211 & 16.6 & 35 & 31.4 & 216 & 15.7 & 1.949 & .057 & $.976-3.896$ & 2.381 & .019 & $1.201-4.722$ \\
\hline
\end{tabular}

Note: $\quad$ Number (n) refers to total number of children within fathers' mental health status.

Percentage $(\%)$ refers to number of children with symptoms within fathers' mental health status.

Cut off for depression and anxiety is top $15 \%$.

One-tailed p-values and confidence intervals; $90 \% \mathrm{CI}=$ confidence interval. 
Table 3: Fathers' offender group versus offspring depression and anxiety

\begin{tabular}{|c|c|c|c|c|c|c|c|c|c|c|c|c|c|c|c|c|c|}
\hline & \multicolumn{2}{|c|}{ NC } & \multicolumn{2}{|c|}{ LO } & \multicolumn{2}{|c|}{$\mathbf{A L}$} & \multicolumn{2}{|c|}{ LCP } & \multicolumn{3}{|c|}{ LO versus NC } & \multicolumn{3}{|c|}{ AL versus NC } & \multicolumn{3}{|c|}{ LCP versus NC } \\
\hline & $\mathrm{n}$ & $\%$ & $\mathrm{n}$ & $\%$ & $\mathrm{n}$ & $\%$ & $\mathrm{n}$ & $\%$ & OR & p-value & $90 \% \mathrm{CI}$ & OR & p-value & $90 \% \mathrm{CI}$ & OR & p-value & $90 \% \mathrm{CI}$ \\
\hline \multicolumn{18}{|c|}{$\%$ depressed or anxious } \\
\hline Total & 303 & 20.5 & 50 & 22.0 & 118 & 25.4 & 66 & 19.7 & 1.131 & .380 & $.585-2.185$ & 1.343 & .129 & $.874-2.064$ & .949 & .439 & $.538-1.673$ \\
\hline Sons & 168 & 20.2 & 22 & 9.1 & 60 & 26.7 & 29 & 17.2 & .405 & .125 & $.111-1.472$ & 1.449 & .153 & $.798-2.631$ & .831 & .360 & $.355-1.943$ \\
\hline Daughters & 135 & 20.7 & 28 & 32.1 & 58 & 24.1 & 37 & 21.6 & 1.872 & .105 & $.822-4.692$ & 1.245 & .272 & $.688-2.253$ & 1.065 & .447 & $.491-2.312$ \\
\hline \multicolumn{18}{|c|}{$\%$ depressed } \\
\hline Total & 303 & 14.5 & 50 & 18.0 & 118 & 16.1 & 66 & 12.1 & .988 & .483 & $.623-1.568$ & 1.081 & .353 & $.769-1.520$ & .879 & .338 & $.529-1.461$ \\
\hline Sons & 168 & 14.3 & 22 & 9.1 & 60 & 21.7 & 29 & 6.9 & .415 & .030 & $.193-.899$ & 1.358 & .129 & $.870-2.125$ & .666 & .197 & $.306-1.452$ \\
\hline Daughters & 135 & 14.8 & 28 & 25.0 & 58 & 10.3 & 37 & 16.2 & 1.436 & .149 & $.812-2.524$ & .833 & .272 & $.508-1.366$ & 1.089 & .415 & $.578-2.041$ \\
\hline \multicolumn{18}{|c|}{$\%$ anxious } \\
\hline Total & 303 & 13.9 & 50 & 14.0 & 118 & 16.9 & 66 & 18.2 & .952 & .362 & $.759-1.195$ & 1.080 & .166 & $.948-1.230$ & 1.123 & .133 & $.946-1.332$ \\
\hline Sons & 168 & 13.7 & 22 & 0.0 & 60 & 11.7 & 29 & 17.2 & .717 & .014 & $.560-.918$ & .931 & .273 & $.765-1.130$ & 1.050 & .382 & $.807-1.364$ \\
\hline Daughters & 135 & 14.1 & 28 & 25.0 & 58 & 22.4 & 37 & 18.9 & 1.146 & .228 & $.848-1.552$ & 1.223 & .026 & $1.032-1.449$ & 1.181 & .122 & $.934-1.496$ \\
\hline
\end{tabular}

Note: $\quad \mathrm{NC}=$ non-convicted, $\mathrm{LO}=$ late-onset offenders, $\mathrm{AL}=$ adolescence-limited offenders, LCP = life-course-persistent offenders.

Number (n) refers to total number of children within fathers' offender group.

Percentage (\%) refers to number of children with symptoms within fathers' offender group.

Reference category in GEE analyses (odds ratios) is non-convicted.

One-tailed p-values and confidence intervals; $90 \% \mathrm{CI}=$ confidence interval. 